\title{
Power Factor Control of Matrix Converter Based Induction Motor Drive
}

\author{
Settar S Keream ${ }^{1}$, Ahmed N Abdalla ${ }^{1}$, Mohd Razali Bin Daud ${ }^{1}$, Ruzlaini ${ }^{1}$ \&youssif Al Mashhadany ${ }^{1}$ \\ ${ }^{1}$ University of Anbar- Univrsity, Pahang, Malaysia \\ Correspondence: Settar S Keream, University of Anbar- Univrsity, Pahang, Malaysia. E-mail: \\ settar_msc@yahoo.com
}

Received: November 29, 2014

Accepted: January 12, $2015 \quad$ Online Published: July 30, 2015

doi:10.5539/mas.v9n8p112

URL: http://dx.doi.org/10.5539/mas.v9n8p112

\begin{abstract}
The Induction Motors utilizing Matrix Converters with Direct Torque Control (DTC) is a great responsibility for motor control scheme with expeditious torque and flux replications. This paper shwed a new power factor control along with the existing DTC matrix converter induction motor drive. The core benefits of the DTC matrix converter are improved with those of the power factor technique, the required voltage vectors is producing under 0.86 input power factor operations. The implementation of this kind of controller is done by using the TMS320F28335. The results validate the good quality and robustness in the proposed system dynamic response and reduction in the transient motor ripple torque.
\end{abstract}

Keywords: power factor, DTC, Matrix converter, induction motor

\section{Introduction}

In last years the direct torque control (DTC) strategy develops the control approaches and one of the high-performances for induction motor due to high response for torque and flux control (Lee, H. H., Nguyen, H. M., Chun, T. W., \& Choi, W. H. 2007, pp. 51-55). The torque and flux of the induction motor can be made by the cull through a look-up table in dirct torque control of the puissance converter voltage space vectors. The highest amelioration of DTC is its structural facileness, then no current controllers, coordinate conversions with PWM are required. Furthermore, the controller does not be influenced by motor factors. Direct torque control can make to be a simple and robust system which reaches a rapid and exact torque control reaction. For such progressive reasons, the advantages of combination matrix converter with DTC method is effectually promising (Chen, D. F., Liao, C. W., \& Yao, K. C. 2007, pp. 101-101). However, some research is quiet being done to decrease the electromagnetic torque ripple, which is its chief problem that leads to the growing stator current deformation noise (Alesina, A., \& Venturini, M. A. R. C. O. G. B. 1989, p101-112). The next approaches are applied to improve the effects of the ripple on the output torque: fuzzy logic controller, the modulation procedures of the SVM, multilevel inverter (Casadei, D., Serra, G., \& Tani, A. 2000, p769-777, Lascu, C., Boldea, I., \& Blaabjerg, F. 2000, p122-130, Buja, G. S., \& Kazmierkowski, M. P. 2004, p744-757, Ghoni, r., abdalla, a. N., \& sujod, z. 2010) and so on. DTC technique was implemented using digital signal processor. Then this algorithm was implemented using ASIC (Application Specific Integrated Circuit) design (Buja, G. S., \& Kazmierkowski, M. P. 2004, p744-757). It is hard to implement DTC utilizing prevalent IC hardware.. The DTC method is normally implemented by sequential calculations on a DSP panel. Nevertheless, as a predictive control scheme, the DTC has a steady-state error formed by the time delay of the long calculations, which depends largely on the control method and hardware performance. Unusual DSP (TMS32010) implementation time of the DTC method for a VSI-fed induction motor is more than $250 \mu$ s (Habetler, T. G., Profumo, F., Pastorelli, M., \& Tolbert, L. M. 1992, p1045-1053.The induction motors are used in seventy to eighty percent of all industrial drive applications due to their simple mechanical construction, reliability, ruggedness, low cost and low maintenance requirement compared to other types of motors. Also it operates at essentially constant speed. These advantages are however suppressed from control point of view. When using an induction motor in industrial drives with high performance demands, the induction motors are non linear high order systems of considerable complexity (Zaghloul, M. E., Meador, J. L., \& Newcomb, R. W. 1994). So, DTC of VSI-fed induction motor based on ANN had been introduced out (Shi, K. L., Chan, T. F., Wong, Y. K., \& Ho, S. L. 2001, p1290-1298, Dung, P. Q., \& Thuong, H. T. N. 2004, pp. 60-63). Also, the originators must possess plentiful experiences on related theories. 
The MC is a captivating converter topology for applications where elements such as elimination of electrolytic capacitors, potential to achieve high power density, reduced size and weight, sinusoidal input and output currents and unity power factor operation are desired. This would include applications ranging from industrial application up to megawatt level, renewable energy applications and additionally conveyance applications. MC applications documented in literature include field oriented control and DTC of motor drives, wind power generation topologies in both squirrel cage induction machine (SCIG) and doubly-alimented induction topologies. The MC is withal being investigated for use in auxiliary drive system for diesel locomotives (Mei, Y., Sun, K., Zhou, D., Huang, L., \& Matsuse, K. 2005, pp. 2476-2483). Although matrix converters (MCs) share the same basic functionality with cycloconverters: to perform single stage ac power conversion with variable magnitude and variable frequency, the MCs differ from the cycloconverters in many aspects. Equipped with four-quadrant bidirectional switches made up of force-commutated devices such as IGBT, a typical MC is able to generate output voltages with either higher or lower frequencies than that of the input. A conventional $\mathrm{MC}$ features inherent four quadrant operation capability, sinusoidal input/output waveforms, and a controllable input power factor (Kolar, J. W., Friedli, T., Rodriguez, J., \& Wheeler, P. W. 2011, pp 4988-5006).

In this paper, the new power factor control is introduced along with the existing DTC control for matrix converter and leading to the reduction of the electromagnetic ripple torque. The experimental results demonstrate the effectiveness of the proposed control scheme was presented.

\section{Modelling of Induction Motor}

Induction motor is nonlinear system and strong coupling multivariable system. In order to enable analysis of the mathematical model of the induction motor, some assumptions must be made, which are; ignore the space harmonics, assuming symmetrical three phase winding, the sine distribution is genrateing the air gap magnatic field, the phenomenon of magnetic saturation is also ignored, eliminating the core loss, disregard the frequency and the influence of temperature change on the winding. Voltage equation of induction motor in stationary dq frame is given in (1):

$$
\left[\begin{array}{l}
V_{s d} \\
V_{s q} \\
V_{r d} \\
V_{r q}
\end{array}\right]=\left[\begin{array}{cccc}
R_{s}+L_{s} \delta & 0 & L_{m} p & 0 \\
0 & R_{s}+L_{s} \delta & 0 & L_{m} \delta \\
L_{m} \delta & \omega L_{m} & R_{r}+L_{r} \delta & \omega L_{r} \\
-\omega L_{m} & L_{m} \delta & -\omega L_{r} & R_{r}+L_{r} \delta
\end{array}\right]\left[\begin{array}{l}
i_{s d} \\
i_{s q} \\
i_{r d} \\
i_{r q}
\end{array}\right]
$$

Where, $L_{s}, L_{r}$ and $L_{m}$ are the stator, rotor and the stator magnetizing inductance, $\omega$ is the angular velocity, $\delta$ is the different symbols for $\delta=\mathrm{d} / \mathrm{dt}$, subscript $s$ and $r$ respectively for the stator and rotor; $d$ and $q$ are for $\mathrm{dq}$ frame. The flux equation is given in (2).

$$
\left[\begin{array}{l}
\psi_{s d} \\
\psi_{s q} \\
\psi_{r d} \\
\psi_{r q}
\end{array}\right]=\left[\begin{array}{cccc}
L_{s} & 0 & L_{m} & 0 \\
0 & L_{s} & 0 & L_{m} \\
L_{m} & 0 & L_{r} & 0 \\
0 & L_{m} & 0 & L_{r}
\end{array}\right]\left[\begin{array}{c}
i_{s d} \\
i_{s q} \\
i_{r d} \\
i_{r q}
\end{array}\right]
$$

Where, $\psi_{\mathrm{sd}}$ and $\psi_{\mathrm{sq}}$ is the dq stator flux, $\psi_{\mathrm{rd}}$ and $\psi_{\mathrm{rq}}$ are the rotor flux. The electromagnetic torque equation is as (3);

$$
T_{e}=\frac{3}{2} p_{n} L_{m}\left(i_{s q} i_{r d}-i_{s d} i_{r q}\right)
$$

According to the flux equation in (2), (3) can be rewritten as (4):

$$
T_{e}=\frac{3}{2} p_{n} L_{m}\left(\psi_{s d} i_{s q}-i_{s d \psi_{s q}}\right)
$$

The mathematical model of the electric drive system equations of motion is done by disregard the electric drive transmission mechanism in the viscous friction and torsional flexibility as,

$$
T_{e}=T_{L}+\frac{J}{p_{n}} d \omega / d t
$$

Where, $T_{L}$ is the load torque, $T_{e}$ is the electromagnetic torque for the motor, $J$ is the moment of inertia and $p_{n}$ is the number of pole pairs for motor. 


\section{Induction Motor (IM) Efficiency and Power Factor Control}

From (1), the IM efficiency and power factor will be calculated. The calculation of the motor active power, $\mathrm{P}$ and reactive power Qare given by,

$$
\begin{gathered}
P=\left(V_{d s} i_{d s}+V_{q s} i_{q s}\right) \\
Q=\left(V_{q s} i_{d s}-V_{d s} i_{q s}\right)
\end{gathered}
$$

Using (1), (6) and (7), the IM efficiency, $\eta$ and power factor, $\cos \varphi$ are derived, without considering the mechanical losses. Therefore, the efficiency can be expressed as,

$$
\begin{aligned}
\eta & =\frac{T_{e} \Omega_{r}}{P}=\frac{T_{e} \omega_{r}}{p_{n} P} \\
& =f_{1}\left(\Delta \omega, \omega_{r}\right)
\end{aligned}
$$

Where, $f_{1}$ is the stator frequency. The active power and power factor is equal to the ratio of the apparent power as in (9),

$$
\begin{gathered}
\cos \varphi=\frac{P}{\sqrt{P^{2}+Q^{2}}} \\
=f_{2}\left(\Delta \omega, \omega_{r}\right)
\end{gathered}
$$

Where, $\quad L_{\sigma}=\frac{L_{s} L_{r}-L_{m}^{2}}{L_{r}} a_{2}=\Gamma_{r}\left(R_{s} \Gamma_{r}+L_{s}-L_{\sigma}\right) \quad, \quad a_{1}=\Gamma_{r}\left(L_{s}-L_{\sigma}\right), \quad a_{0}=R_{s}, \quad b_{3}=b_{2}=L_{\sigma} \Gamma_{r}^{2}$, $b_{1}=b_{0}=L_{s}, f_{2}$ is the rotor frequency and $\Gamma_{r}=\frac{L_{r}}{R_{r}}$, is the rotor time constant.

Equation (8) and (9) show that the IM efficiency and power factor is the relationship of the rotor and a slip function angular frequency. In other words, when the rotor and slip angular frequency is constant, the value of the efficiency and power factor is also constant. Thus, the maximum efficiency of the IM power factor values can be calculated.

The relationship between the IM motor efficiency and power factor analysis was done using Matlab 10.0 software. The selected motor parameters are as follows;

$$
\begin{gathered}
P=0.75 \mathrm{kw}, \mathrm{V}=215 \mathrm{~V}, n=1000 \mathrm{rpm}, T=5.52 \mathrm{Nm}, R_{1}=5.89 \Omega, L_{11}=.061 \mathrm{H}, R_{2}^{\prime}=5.375 \Omega, L_{12}^{\prime}= \\
0.013 \mathrm{H}, L_{m}=0.149 \mathrm{H}, \mathrm{J}=0.02 \mathrm{~kg} \cdot \mathrm{m}^{2}, p=4 .
\end{gathered}
$$

Figure 1 is the graph of efficiency versus the rotor and slip frequency. When $\Delta \omega$ is fixed, the motor efficiency increases with the increasing of the rotor angular frequency. However, when $\omega_{r}$ is fixed, the motor efficiency is increases at first, and starting to show the decreasing trend with the maximum changing process. The value is the maximum efficiency with the increasing of the rotor angular frequency.

Figure 2 shows that the power factor has small changes when the speed is large, but when the speed is lowered to its maximum of about $10 \%$, the power factor increases rapidly. The curve bends of Figure 2 shows the clear trend. The power factor increases with the increases of the slip frequency when $\omega_{r}$ is fixed.

From the previous analysis, it was concluded that the power factor is not at its highest when the efficiency is maximized, but the relationship is one to one. Thus, the power factor can be used as the control volume. The implementation of closed-loop power factor control by comparison of the given power factor with the actual can be used to adjust the motor terminal voltage in real time and allowing the system to achieve the optimum efficiency. From (8), the value of the efficiency derivation can be drawn as (10):

$$
\frac{\delta \eta}{\delta \Delta \omega}=\frac{\delta f(\Delta \omega)}{\delta \Delta \omega}=0
$$

And 


$$
\Delta \omega^{B}=\sqrt{\frac{R_{s} R_{r}^{2}}{R_{r} L_{m}^{2}+R_{s} L_{r}^{2}}}
$$

$\Delta \omega^{B}$ is the efficiency of a rotor angular frequency corresponding to the maximum point of the slip frequency. From (9), the efficiency of a rotor angular frequency corresponding to the maximum point of the power factor is given in (12):

$$
\cos \varphi^{B}=f_{2}\left(\Delta \omega^{B}, \omega_{r}\right)
$$

From (12), the $\Delta \omega^{B}$ andcos $\varphi^{B}$ are the motor parameters to achieve the maximum efficiency. From (12), the best power factor angle of the rotor frequency curve can be calculated and shown in Figure 3.

It can be seen in the normal operating speed range, the best power factor changes from 0.55 to 0.75 . From the control perspective, the power factor should be controlled along with the changes of a given speed so that it is always running at a maximum efficiency state. As can be seen from the above analysis, the power factor control, is the motor slip frequency control for different operating conditions by adjusting the input voltage to keep the slip frequency $\Delta \omega^{B}$ around $\Delta \omega$.

The use of the power factor closed-loop control system will optimize the efficiency of the establishment in constant pressure based on the frequency ratio control to control the amount of the power factor, compromising in the stability of the actual power factor. The system block diagram is shown in Figure 4.

Efficiency optimization control system includes the following main modules: the best power factor calculation, function generator, power factor measurement, the reference wave generation, SVPWM, the drive circuit, MC, efficiency calculations, IM and other parts. The system model is shown in Figure 5.

The best angle for a given power factor according to the method described previously calculates the optimum power factor for a given value as the changes of the rotor speed.

\section{Results and Discussion}

The proposed algorithms were implemented in a TMS320F28335 DSP and the system setup is shown in Figure 6. Figure 7 shows the simulation and experimental results for the flux at a given amplitude of $1.5 \mathrm{~Wb}$. The time taken for the flux motor to reach the steady-state is less than $0.05 \mathrm{~s}$ with very small fluctuations for the proposed method. Figure 8 shows the response of torque when the torque is changed from $6 \mathrm{Nm}$ to $12 \mathrm{Nm}$. Figure 8 (a) is the result without using the proposed method with large among of torque ripple as compared to the proposed method. Figure 9 shows the response of phase a stator current when the torque is changed from $6 \mathrm{Nm}$ to $12 \mathrm{Nm}$ with the stator current response to the changes of torque command. Some noise was observed for the stator current without using the proposed method as in Figure 9 (a).

Figure 10 (b) shows the torque response with the speed increased from 500rpm to 1000rpm with. The greater torque impact is achieved with the speed increases at less than $0.05 \mathrm{~s}$. When the curve of the speed changes in Figure 11 (a), the torque response changes with the speed changes. The electromagnetic torque is reversed following the speed command as in Figure 11 (c).

\section{Conclusions}

The proposed power factor control in this paper will optimize the efficiency of the establishment in constant pressure based on the frequency ratio control to control the amount of the power factor, compromising in the stability of the actual power factor. The power factor control reduced the torque ripple hence improving the matrix converter performance. 


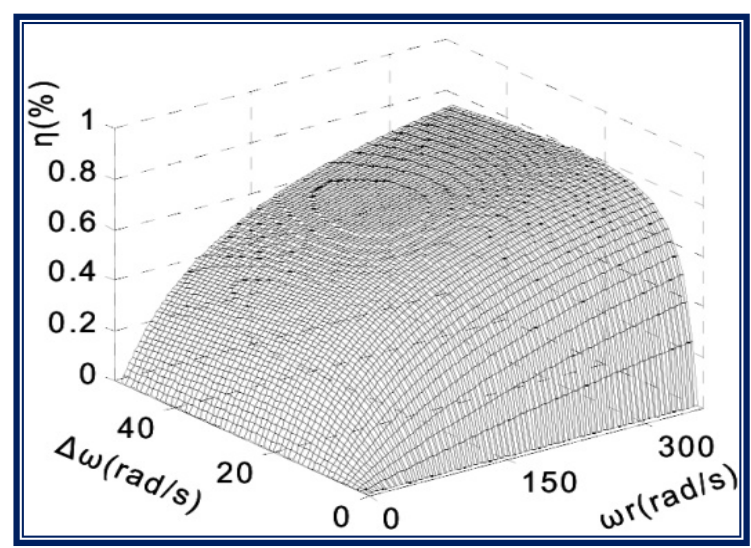

Figure 1. Efficiency versus rotor and slip frequency

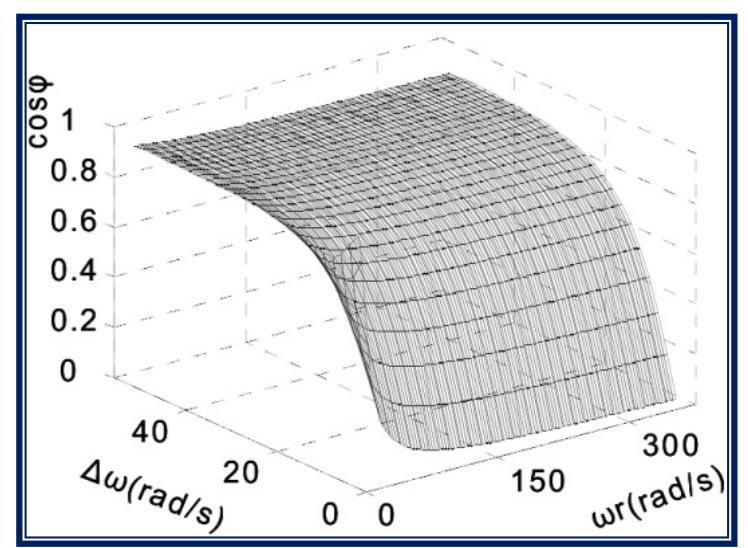

Figure 2. Power factor versus rotor and slip frequency

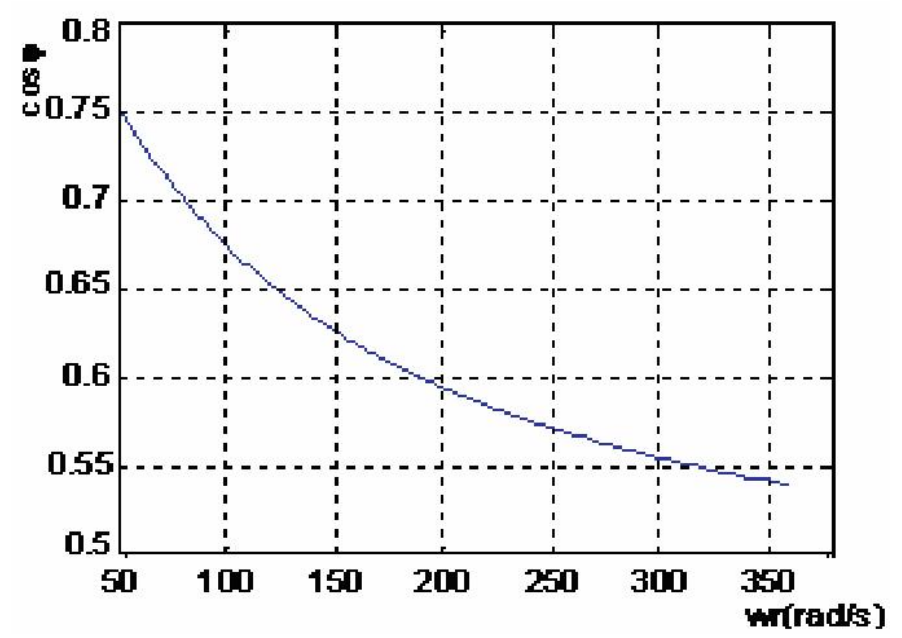

Figure 3. Relation between the rotor frequency and best power factor

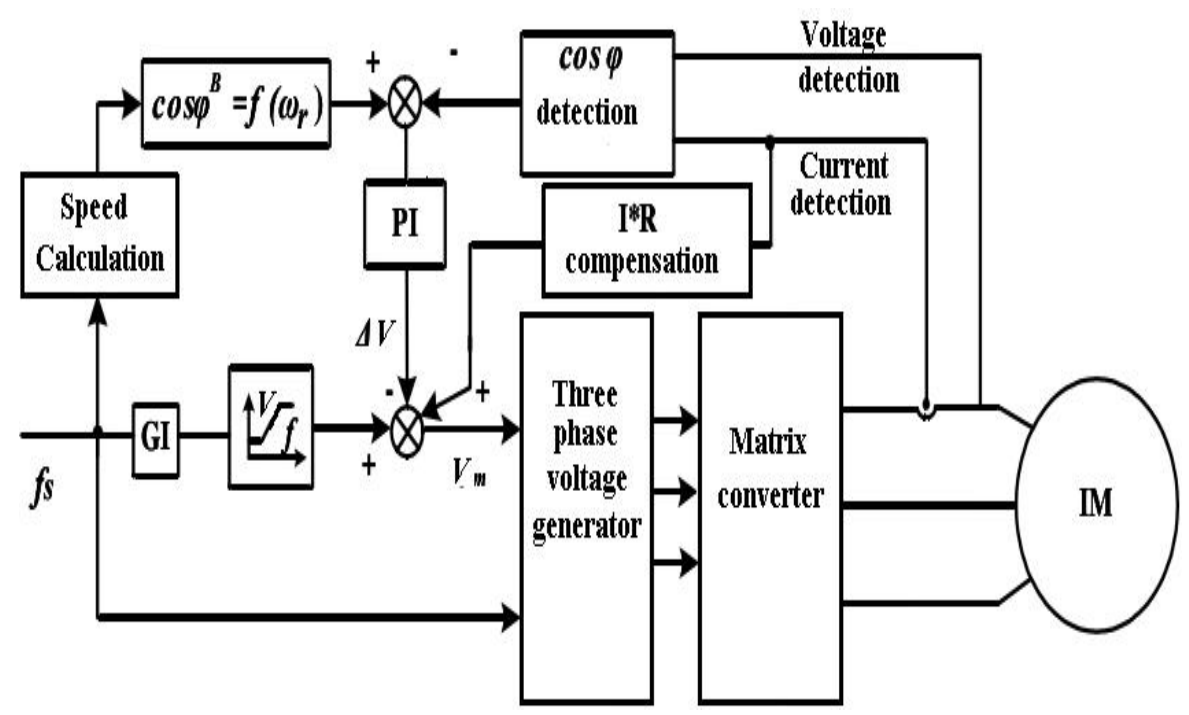

Figure 4. Efficiency optimization control system 


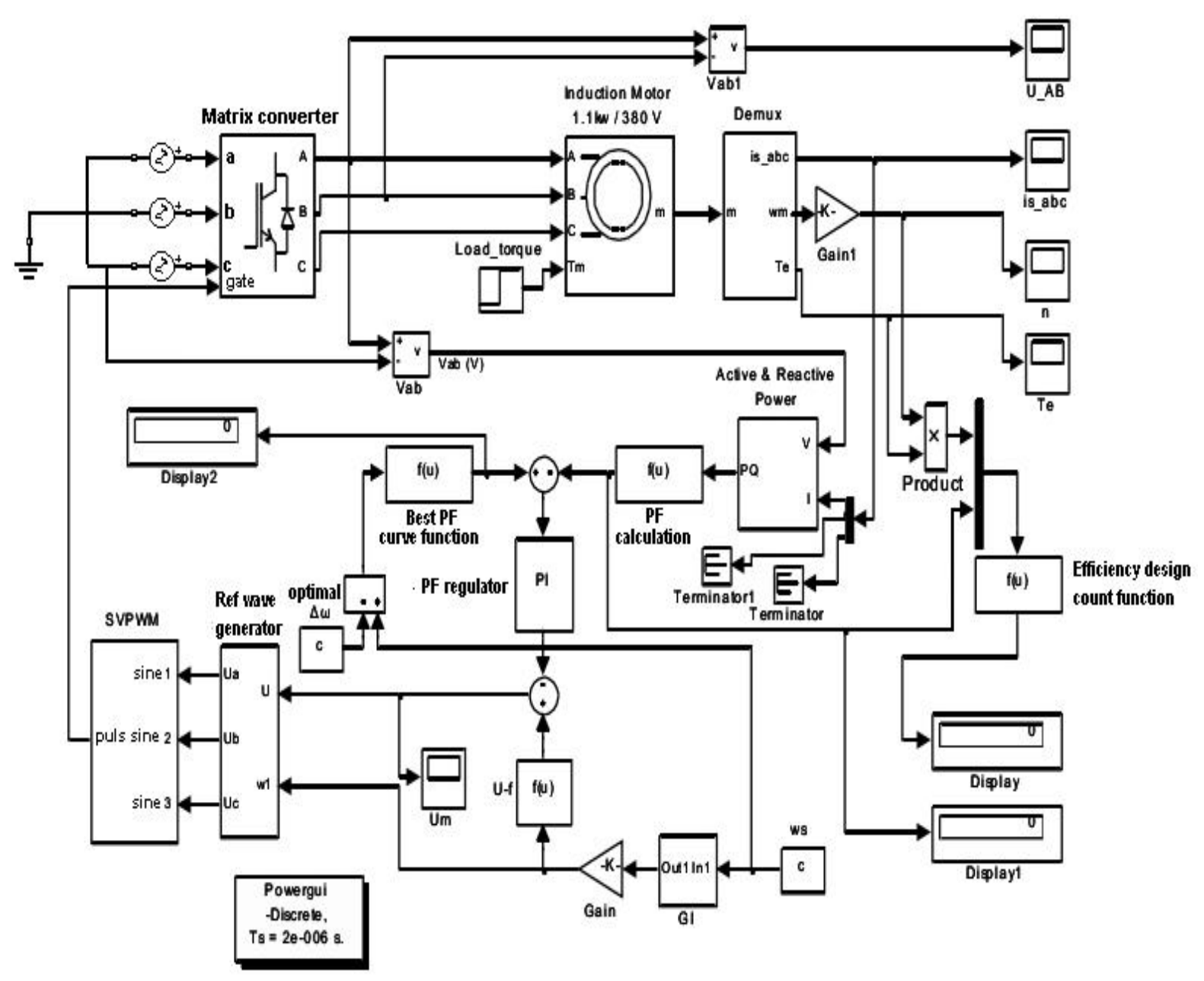

Figure 5. Modelling of efficiency optimization system

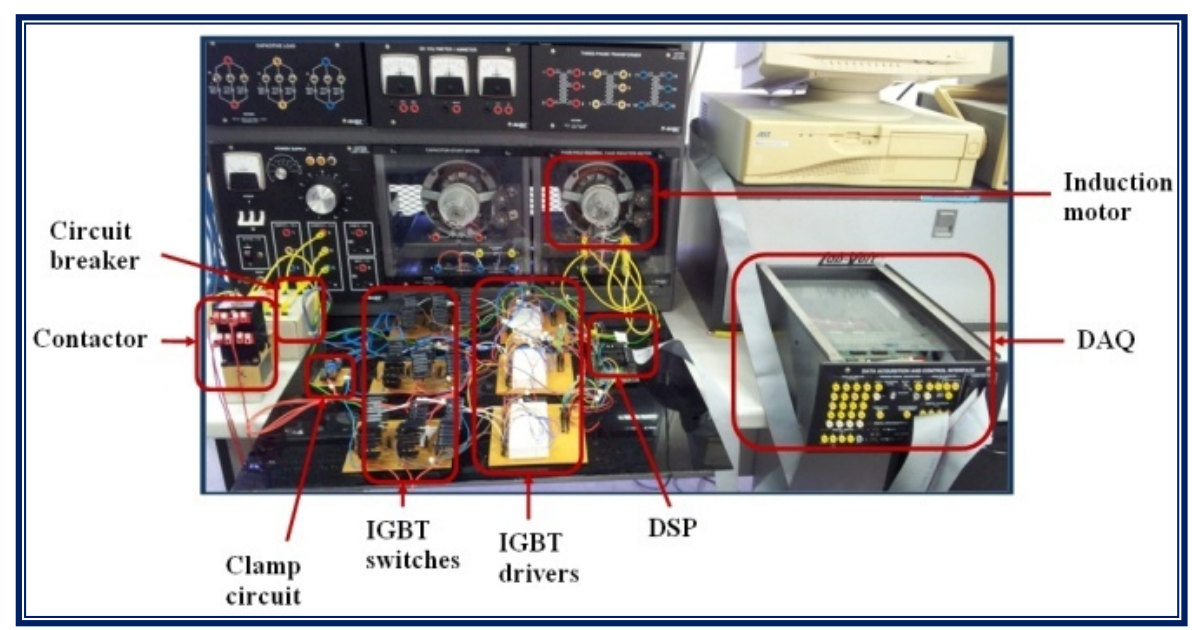

Figure 6. Complete MC hardware 


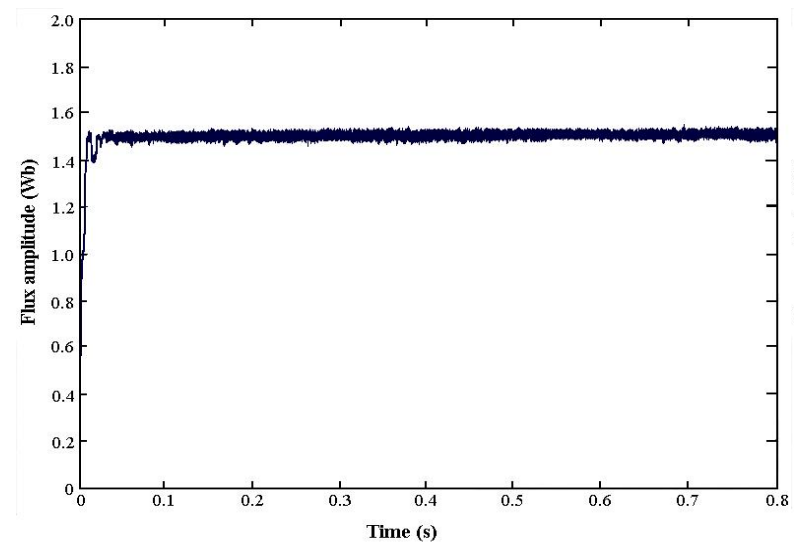

Figure 7 (a)

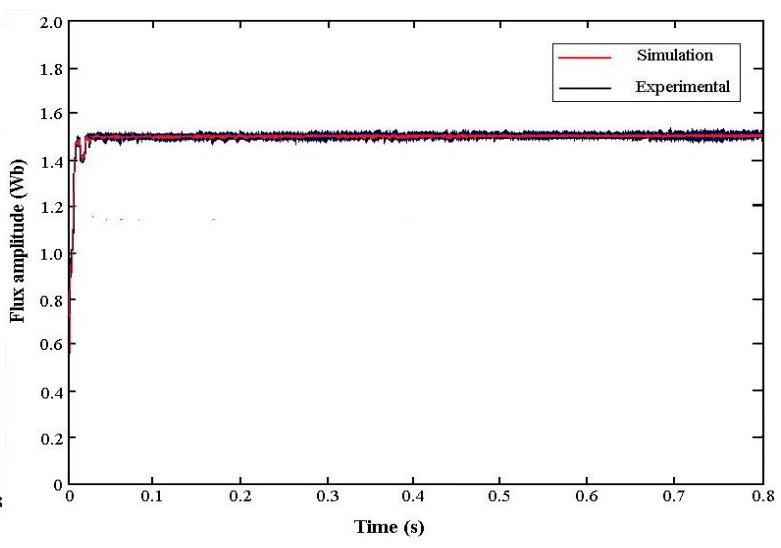

Figure 7 (b)

Figure 7. Flux amplitude; (a) without proposed method; (b) with the proposed method

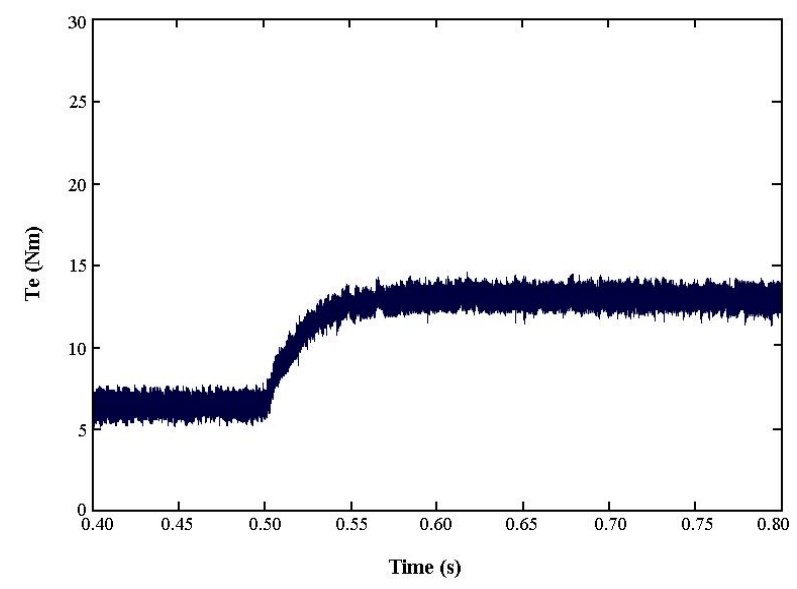

Figure 8 (a)

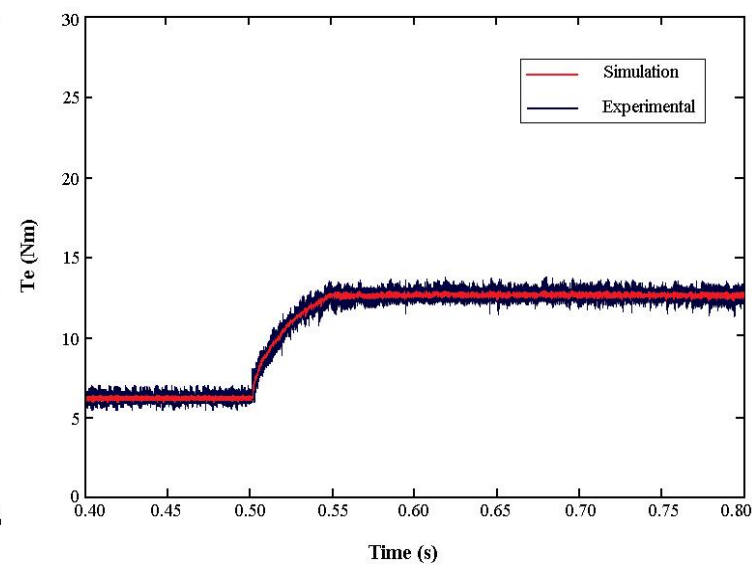

Figure 8 (b)

Figure 8 . Motor torque; (a) Torque changes from $6 \mathrm{Nm}$ to $12 \mathrm{Nm}$ without proposed system; (b) Torque changes from $6 \mathrm{Nm}$ to $12 \mathrm{Nm}$ with the proposed system

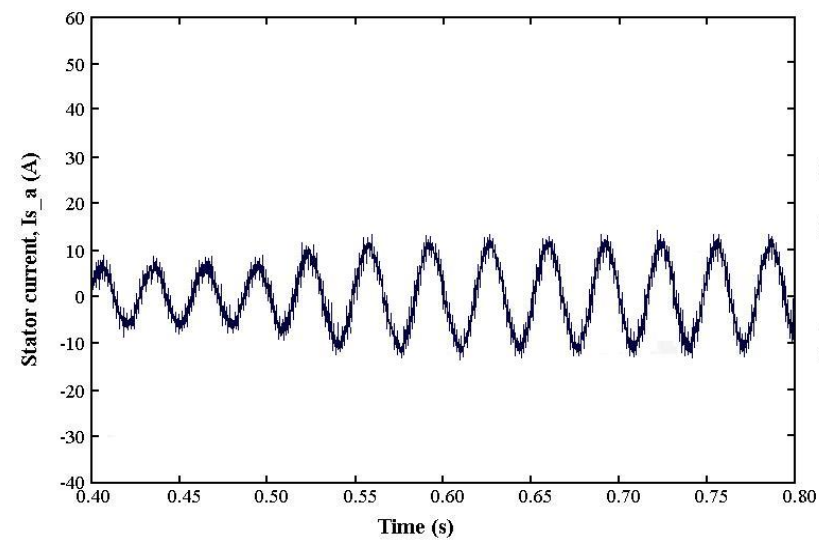

Figure 9 (a)

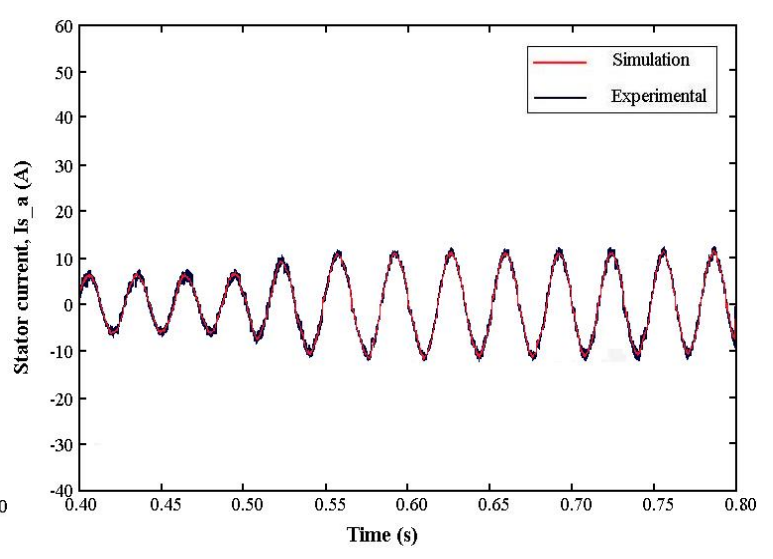

Figure 9 (b)

Figure 9. Stator current (a) without proposed method; (b) with the proposed method 


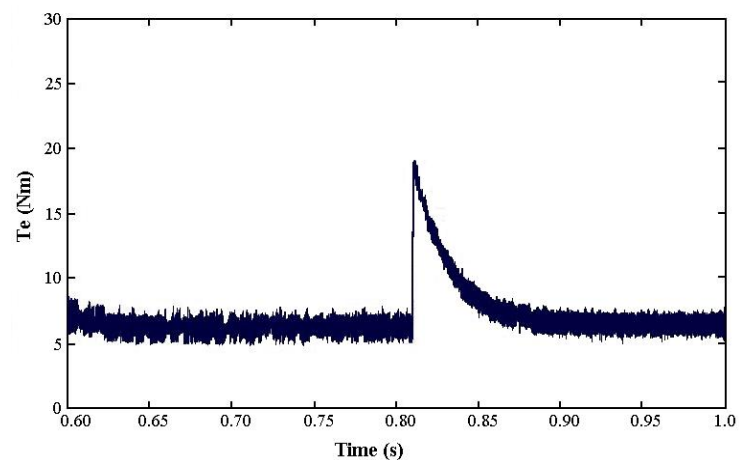

Figure 10 (a)

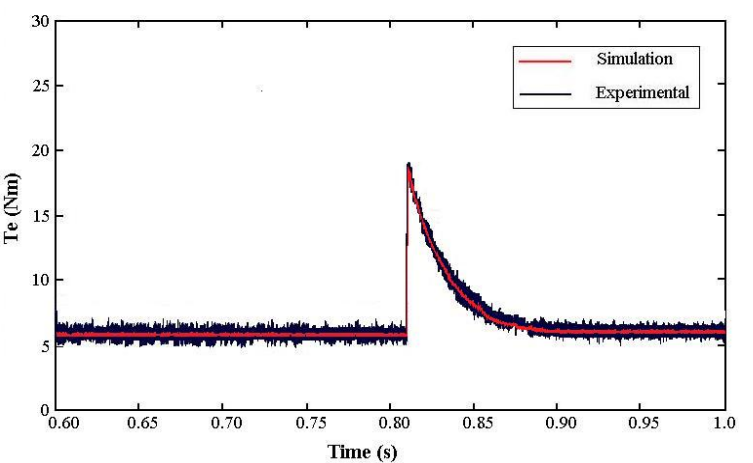

Figure 10 (b)

Figure 10. Effect of changes the motor speed of the torque response (a) speed from 500rpm to 1000rpm (b) Torque response without proposed method

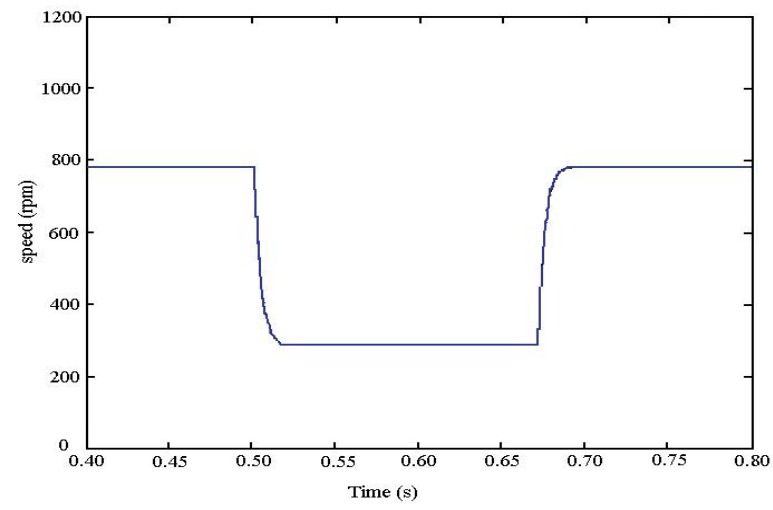

Figure 11 (a)

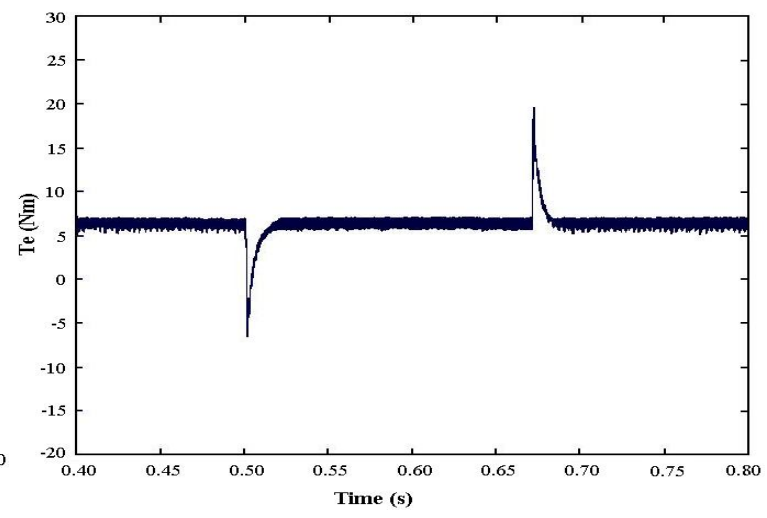

Figure $11(b)$

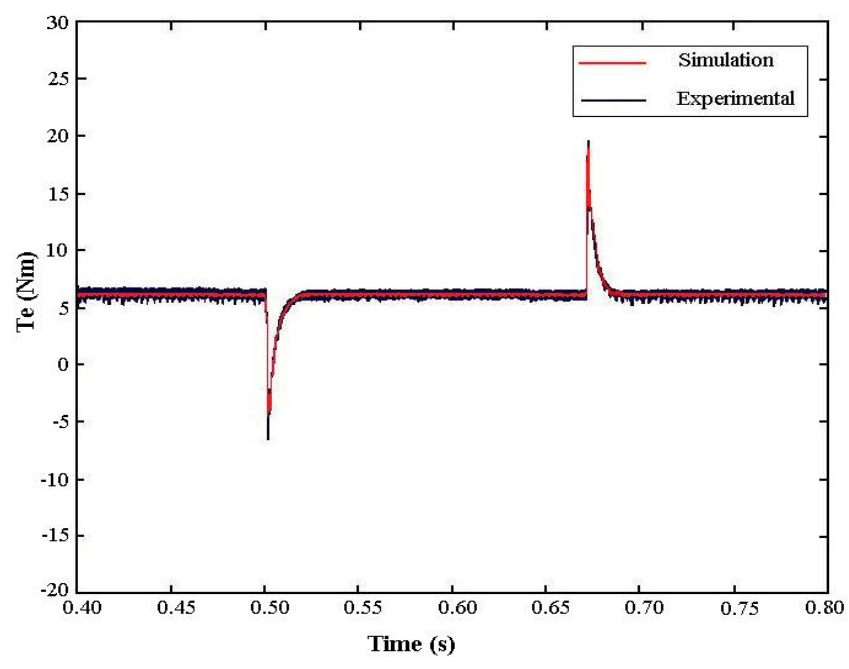

Figure 11 (c)

Figure 11. Dynamic changes of motor speed (a) speed (b) torque responses without proposed system (c) torque responses with the proposed system

\section{References}

Alesina, A., \& Venturini, M. A. R. C. O. G. B. (1989). Analysis and design of optimum-amplitude nine-switch direct AC-AC converters. IEEE Transactions on Power Electronics, 4(1), 101-112. 
http://dx.doi.org/10.1109/63.21879

Buja, G. S., \& Kazmierkowski, M. P. (2004). Direct torque control of PWM inverter-fed AC motors-a survey. IEEE Transactions on Industrial Electronics, 51(4), 744-757. http://dx.doi.org/10.1109/TIE.2004.831717

Casadei, D., Serra, G., \& Tani, A. (2000). Implementation of a direct control algorithm for induction motors based on discrete space vector modulation. IEEE Transactions on Power Electronics, 15(4), 769-777. http://dx.doi.org/10.1109/63.849048

Chen, D. F., Liao, C. W., \& Yao, K. C. (2007, September). Direct torque control for a matrix converter based on induction motor drive systems (pp. 101-101). In Innovative Computing, IEEE.Second International Conference on Information and Control, 2007. ICICIC'07. http://dx.doi.org/10.1109/ICICIC.2007.268

Dung, P. Q., \& Thuong, H. T. N. (2004). Direct torque control for induction motor using ANN. In The 2004 International Symposium on Advanced Science and Engineering, HCM City, Vietnam (pp. 60-63).

Ghoni, R., Abdalla, A. N., \& Sujod, Z. (2010). Direct torque control for matrix converter-fed three phase induction motor with hybrid pso. Journal of Theoretical \& Applied Information Technology, 13. Retrieved from http://www.jatit.org/

Habetler, T. G., Profumo, F., Pastorelli, M., \& Tolbert, L. M. (1992). Direct torque control of induction machines using space vector modulation. IEEE Transactions on Industry Applications, 28(5), 1045-1053. http://dx.doi.org/10.1109/28.158828

Kolar, J. W., Friedli, T., Rodriguez, J., \& Wheeler, P. W. (2011). Review of three-phase PWM AC-AC converter topologies. IEEE Transactions on Industrial Electronics, 58(11), 4988-5006. http://dx.doi.org/10.1109/TIE.2011.2159353

Lascu, C., Boldea, I., \& Blaabjerg, F. (2000). A modified direct torque control for induction motor sensorless drive. IEEE Transactions on Industry Applications, 36(1), 122-130. http://dx.doi.org/10.1109/28.821806

Lee, H. H., Nguyen, H. M., Chun, T. W., \& Choi, W. H. (2007, October). Implementation of direct torque control method using matrix converter fed induction motor (pp. 51-55). IEEE.International Forum on Strategic Technology, 2007. IFOST 2007. http://dx.doi.org/10.1109/IFOST.2007.4798517

Mei, Y., Sun, K., Zhou, D., Huang, L., \& Matsuse, K. (2005, October). Application of matrix converter in auxiliary drive system for Diesel locomotives. IEEE Conference Record of the 2005 Fourtieth IAS Annual Meeting In Industry Applications Conference, 2005 (Vol. 4, pp. 2476-2483). http://dx.doi.org/10.1109/IAS.2005.1518808

Shi, K. L., Chan, T. F., Wong, Y. K., \& Ho, S. L. (2001). Direct self control of induction motor based on neural network. IEEE Transactions on Industry Applications, 37(5), 1290-1298. $\mathrm{http}: / / \mathrm{dx}$. doi.org/10.1109/28.952504

Zaghloul, M. E., Meador, J. L., \& Newcomb, R. W. (1994). Silicon implementation of pulse coded neural networks. Kluwer Academic Publishers. ISBN:0792394496.

\section{Copyrights}

Copyright for this article is retained by the author(s), with first publication rights granted to the journal.

This is an open-access article distributed under the terms and conditions of the Creative Commons Attribution license (http://creativecommons.org/licenses/by/3.0/). 